\title{
PRECIPITAÇÃO INTERNA E INTERCEPTAÇÃO DA CHUVA EM DUAS ESPÉCIES ARBÓREAS URBANAS ${ }^{1}$
}

\author{
Luzia Ferreira da Silva ${ }^{2}$ Ana Maria Liner Pereira Lima ${ }^{3}$, Demóstenes Ferreira da Silva \\ Filho $^{4}$ e Hilton Thadeu Zarate do Couto ${ }^{5}$
}

(recebido em 15.04. 2009 e aceito para publicação em 03.09.2009)

\begin{abstract}
RESUMO
As enchentes nas cidades trazem grandes transtornos para a população e Órgãos Públicos, nesse sentido várias medidas são tomadas no intuito de diminuir esses problemas. As copas das árvores podem contribuir para amenizar esses efeitos, que se tornaram tão comuns, devido aos eventos extremos que estão acontecendo em toda parte do mundo. Com o objetivo de mostrar o processo de interceptação da chuva, o experimento foi realizado no campus da ESALQ/USP, no período de janeiro e fevereiro de 2007, nas espécies adultas de Caesalpinia pluviosa DC. (Fabaceae: Caesalpinioideae) ou sibipiruna e Tipuana tipu O. Kuntze (Fabaceae: Faboideae) ou tipuana. A água foi coletada por meio de baldes de sete litros de capacidade, tanto na extremidade como no centro da copa e, posteriormente, os dados formam tabulados em milímetros de água. As porcentagens médias de interceptação foram maiores no centro da copa de tipuana $(59,40 \%)$ e apenas na extremidade de um indívíduo de sibipiruna $(60,6 \%)$. A precipitação interna (PI) apresentou alta correlação com a precipitação total (PT), no centro da copa de tipuana; o escoamento pelo tronco (Et) e a interceptação (I) tiveram baixa correlação com a PT, nas duas espécies. Portanto, ambas as espécies tiveram bons resultados nos processos de interceptação, sendo que a tipuana mostrou maior destaque para captação de água.
\end{abstract}

Palavras-chave: sibipiruna, tipuana, enchentes, cidades

\footnotetext{
${ }^{1}$ Parte da tese de doutorado da primeira autora, bolsista CAPES.

${ }^{2}$ Engenheira Agrônoma, Prof. Dr. Universidade Federal Rural do Pernambuco - Campus de Serra Talhada. Rua Emílio Covessi, n. 605 - Apto. 303, Bairro São Vito, Americana - SP. CEP: 13.472-100. E-mail: Ifsilva68@hotmail.com

3 Engenheira Agrônoma, Professora Doutora do Departamento de Produção Vegetal, ESALQ/USP, amlplima@esalq.usp.br.

${ }^{4}$ Professor Doutor do Departamento de Ciências Florestais, ESALQ/USP, dfsilva@esalq.usp.br.

${ }^{5}$ Professor Doutor do Departamento de Ciências Florestais, ESALQ/USP,

htzcouto@esalq.usp.br.
}

REVSBAU, Piracicaba - SP, v.4, n.3, p.32 - 48, 2009 


\title{
THROUGHFALL AND RAINFALL INTERCEPTION IN TWO URBAN TREE
}

\begin{abstract}
The flooding in cities brings inconvenience major to the population and public organ, in those feel various measures are taken in aim to reduce these problems. The canopy of trees can help mitigate these effects, which have become so common due of the extreme events that are happening everywhere the world. Aiming to show the process of rainfall interception, the experiment was conducted on the campus of ESALQ / USP, from January to February 2007, in the adult species of Caesalpinia pluviosa DC. (Fabaceae: Caesalpinioideae) or sibipiruna and Tipuana tipu O. Kuntze (Fabaceae: Faboideae) or Tipuana. Water was collected using seven litre pails, by the edges and in the centre of crow and then the data was tabulated in millimeters of water. The average percentage of interception was higher in the center of the crow of Tipuana (59.40\%) and only the edge of an individual of sibipiruna (60.6\%). High correlation of throufghfall (Th) with gross precipitation $(\mathrm{Pg})$ in the center of tipuana crow and stemflow (St) and interception (I) had low correlation with the $\mathrm{Pg}$, in two species. Therefore, both species had good results in the processes of interception, the tipuana showed greater emphasis on retention of water.
\end{abstract}

Key words: sibipiruna, tipuana, flooding, cities 


\section{INTRODUÇÃO}

O meio ambiente urbano vem sofrendo grandes transformações pelo homem à medida que novos equipamentos são inseridos, principalmente os materiais de construção civil na cidade, que geram ambiente artificial, capaz de alterar o balanço de energia na atmosfera urbana.

Os elementos climáticos que mais interferem no balanço de energia são: temperatura e umidade relativa do ar (ilha de calor, ilha de frescor, conforto e desconforto térmico), os ventos (diretamente ligados à dispersão dos poluentes) e, nas cidades tropicais, a precipitação (inundações) (MENDONÇA, 1994).

As mudanças na paisagem, decorrentes do surgimento e crescimento das cidades, geram mudanças no comportamento da atmosfera sobre a cidade. Existe um propósito de que as alterações na cobertura vegetal e no uso do solo, com a total ou parcial substituição da vegetação pela área urbana, em algumas partes das metrópoles, provocaram mudanças no clima local, levando a formação do Clima Urbano próprio (AMORIM, 2000).

No meio urbano e, especialmente, nas metrópoles, essas alterações proporcionarão perdas na economia e na qualidade de vida das populações. Com respeito ao clima urbano, destacam-se a formação de ilhas de calor, a falta de condições para a dispersão da poluição atmosférica e a baixa umidade relativa do ar, bem como a ocorrência de chuvas concentradas em determinados períodos do ano que, associada à intensa impermeabilização do solo, vem ocasionar as enchentes e os deslizamentos de encostas (LOMBARDO, 1985).

Pode-se perceber que os problemas ambientais emergem como resultado do processo de produção da própria cidade. Em conseqüência, o meio urbano tende a acumular e difundir, com a mesma intensidade, o caos, o desperdício e a degradação, que se tornam mais graves quanto maior for a cidade (GIACOMINI, 1981).

Segundo Spirn (1996), a causa da perda de importância da natureza, inserida na cidade, provoca uma péssima qualidade de vida urbana. Os ambientes naturais não são benignos nem hostis à humanidade, porque, uma vez reconhecidos e aproveitados, representam um poderoso recurso para a conformação de um habitat urbano benéfico.

A permeabilidade do solo é um dos principais estudos da hidrologia urbana e o aumento indiscriminado de áreas impermeáveis é um dos principais agentes do incremento do escoamento superficial e a ocorrência de enchentes (CENTENO et al., 2003).

A quantidade de escoamento superficial aumenta com o grau de urbanização, pela mudança do uso do solo e não pela incapacidade das redes pluviais (OKE, 1978).

REVSBAU, Piracicaba - SP, v.4, n.3, p.32- 48, 2009 
A alta impermeabilização do solo ao longo da microbacia gera vários problemas, tais como, aumento no escoamento superficial, devido a pouca infiltração de água no solo; erosão, com mudanças das características originais; alteração no microclima em virtude do aumento da temperatura e das precipitações convectivas pela intensa urbanização e alterações no regime do rio tanto para jusante (retificações e canalizações) como para montante (barragens). Esses problemas se agravam devido à gestão deficiente que é resultado da falta de mecanismos legais e administrativos, provocados pela crescente e desordenada urbanização. Quando ocorrem chuvas intensas, a situação se agrava mais, principalmente no verão, que causam enchentes em vários pontos da cidade (ZUFFO, 2006).

As enchentes são intensificadas, principalmente, pelo crescimento das áreas impermeabilizadas, pela pavimentação dos leitos carroçáveis e pelas edificações, em que as áreas de drenagem natural são substituídas por concreto, provocando um colapso no sistema das galerias de águas pluviais e de esgotos. Em conseqüência, acarreta o transbordamento de água da chuva pelas galerias e rios que cortam a cidade, o que causa um significativo aumento de doenças de veiculação hídrica.

Além dos agravantes das enchentes, o que se observa é a supressão de espécies de grande porte, devido aos prejuízos que a população e Órgãos Públicos levantam e, em conseqüência as substituem por arbustos. Entretanto, um estudo mais aprofundado sobre a interceptação da água da chuva pelas copas das árvores, nunca foi desenvolvido, principalmente nas condições das cidades tropicais e pode mostrar um dos benefícios que as árvores fornecem para minimizar as enchentes.

Dessa forma, o trabalho tem como objetivo quantificar, de maneira experimental, a interceptação de águas pelas copas das espécies de sibipiruna e tipuana, em chuvas torrenciais presentes na época de verão.

\section{MATERIAL E MÉTODOS}

\section{Local de estudo}

O município de Piracicaba se encontra entre as coordenadas geográficas de $22^{\circ}$ $42^{\prime} 30^{\prime \prime}$ de latitude sul e $47^{\circ} 38^{\prime} 00^{\prime \prime}$ de longitude a oeste, com altitude média S.N.M. de $546 \mathrm{~m}$. O clima é do tipo mesotérmico de inverno seco. A precipitação média anual é, aproximadamente, $1.280 \mathrm{~mm}$, sendo que, cerca de $1.000 \mathrm{~mm}$ ou $78 \%$ desse total, caem durante a estação chuvosa, que vai de outubro a março (verão) (Estação Meteorológica da ESALQ/USP). O período experimental ocorreu nos meses de janeiro a fevereiro de 2007. A temperatura média anual é de $20^{\circ} \mathrm{C}$. 
A Caesalpinia pluviosa DC. (sibipiruna) e a Tipuana tipu O. Kuntze (tipuana) foram plantadas na década de 50, no campus da Escola Superior de Agricultura "Luiz de Queiroz", em Piracicaba/SP. Em espécies muito jovens, os valores de interceptação são difíceis de verificar, segundo Geiger (1961), dessa forma, foram escolhidas espécies adultas que representam as mesmas alturas de árvores plantadas nas calçadas.

\section{Espécies estudadas}

A sibipiruna é uma espécie ornamental, com potencial madeireiro; encontrada principalmente, na região de Mata Atlântica do Rio de Janeiro, sul da Bahia e no Pantanal Mato-Grossense. A árvore é semidecídua e heliófita, produzindo, anualmente, grande quantidade de sementes. Suas flores são zigomorficas, racemosas terminais, amarelas, dispostas em cachos cônicos e eretos, com ocorrência na primavera. A folhagem cai parcialmente nos meses de inverno e é composta bi-pinadas, sem glândulas no ráquis e de pequenos folíolos. Os frutos são deiscentes de cor bege-claro, tipo legume achatado, com cerca de $3 \mathrm{~cm}$ de diâmetro. Seu porte pode chegar até 20 metros de altura, com copa arredondada de aproximadamente 15 metros de diâmetro e seus ramos são ortotrópicos, que crescem verticalmente (HALLÉ et al., 1978; LORENZI, 1992; VIDAL; VIDAL, 1992; ENDRESS, 1994).

A tipuana é nativa da Argentina e da Bolívia e foi introduzida em vários outros países, onde é cultivada como ornamental e é mais comum no sul do Brasil. Tem florescimento na primavera, com cachos de flores amarelo-ouro, de simetria zigomorfa e aroma agradável. Seus frutos são indeiscentes, tipo sâmara, com pericarpo seco e alado, monospérmicos e mais freqüentes no outono; o tronco é rústico, de casca escura e superfície enrugada. As folhas são compostas pinadas de folíolos ovais que caem no inverno e com pulvinos e estípulas. O porte pode atingir até 25 metros de altura, com copa larga de até 20 metros de diâmetro e seus ramos plagiotrópicos são quase horizontais (HALLÉ et al., 1978; VIDAL; VIDAL, 1992; MARTINS; OLIVEIRA, 2001).

As espécies apresentaram divergências nos modelos de ramificação (ortotrópicos e plagiotrópicos), na estrutura da folha (folíolos pequenos e formato oval), nas flores (terminais e não terminais), nos frutos (deiscente-legume e indeiscentesâmara) e no caule (superfície menos enrugada e muito enrugada), mostrados na Figura 1.

Cada espécie estudada teve seis indivíduos, sendo três isolados de sibipiruna, com a identificação de $\mathrm{S} 1$, S5 e $\mathrm{S} 6$ e três em grupo ou com as copas próximas, indicados por S234 e três isolados de tipuanas, com a identificação T1, T5 e T6 e três 
em grupo ou com as copas próximas, definidas como T234. Eles estavam distribuídos em uma área de 1 hectare, aproximadamente, distanciados de 6 a $100 \mathrm{~m}$ e foram avaliados o diâmetro à altura do peito (DAP), a altura, o diâmetro e a área da copa.

Os valores do diâmetro e área da copa foram registrados por meio de imagem aérea de videografia, obtida em agosto de 2005. O aparelho hipsômetro foi usado para medir a altura das árvores. As medidas do DAP e da altura dos indivíduos, em grupo, foram feitas pela média aritmética dos três indivíduos.

(a)

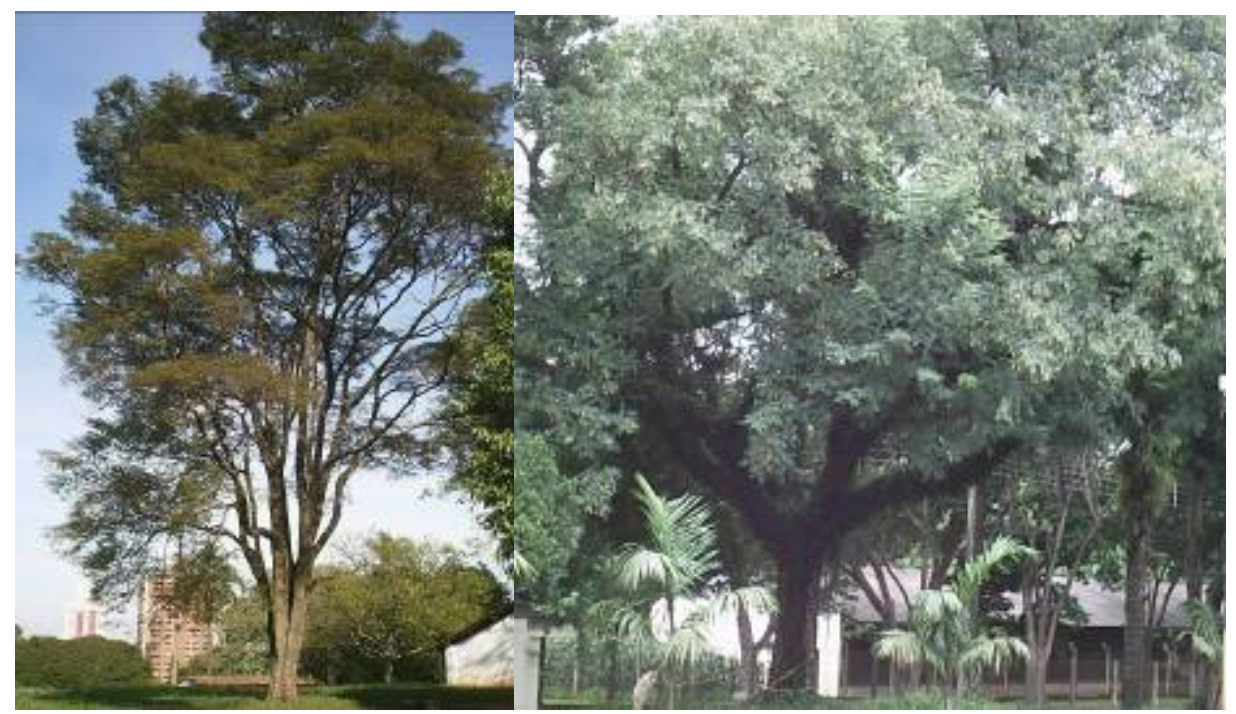

Fonte: autora

(b)

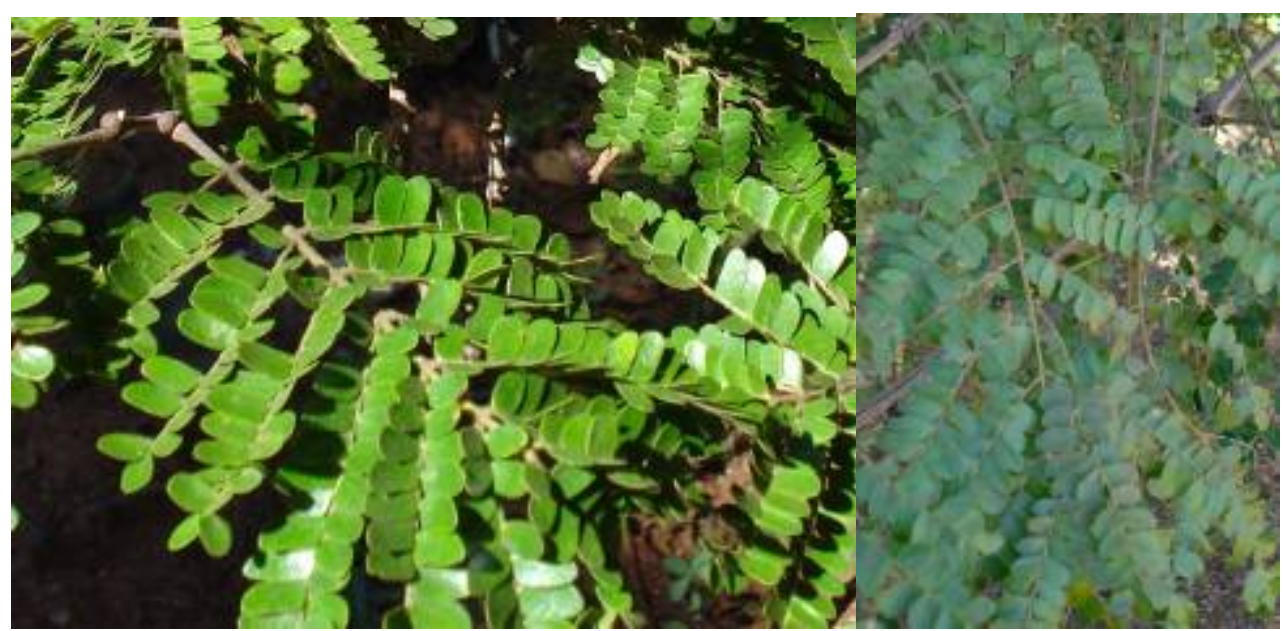

Fonte: timblindim.wordpress.com 
(c)

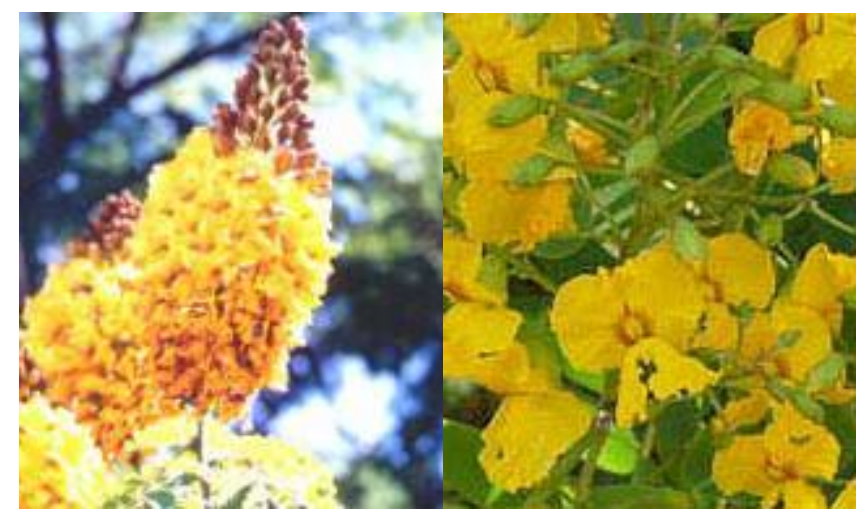

Fonte: www.vilamada.com.br, www.portalmundodasflores.com.br

(d)

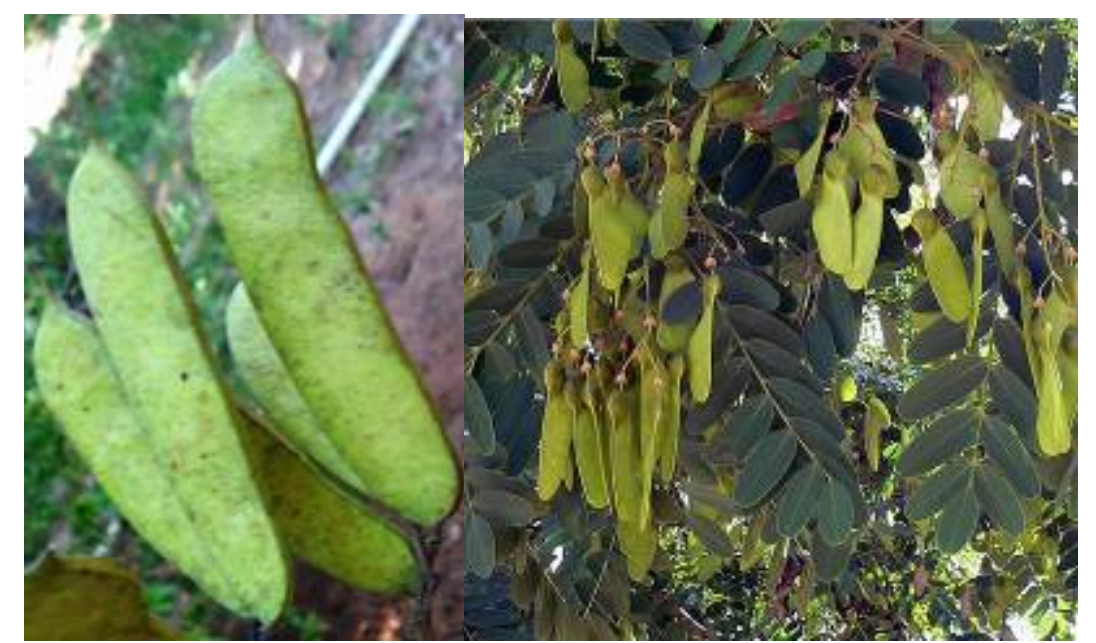

Fonte: fabian.balearweb.net/post, timblindim.wordpress.com

(e)

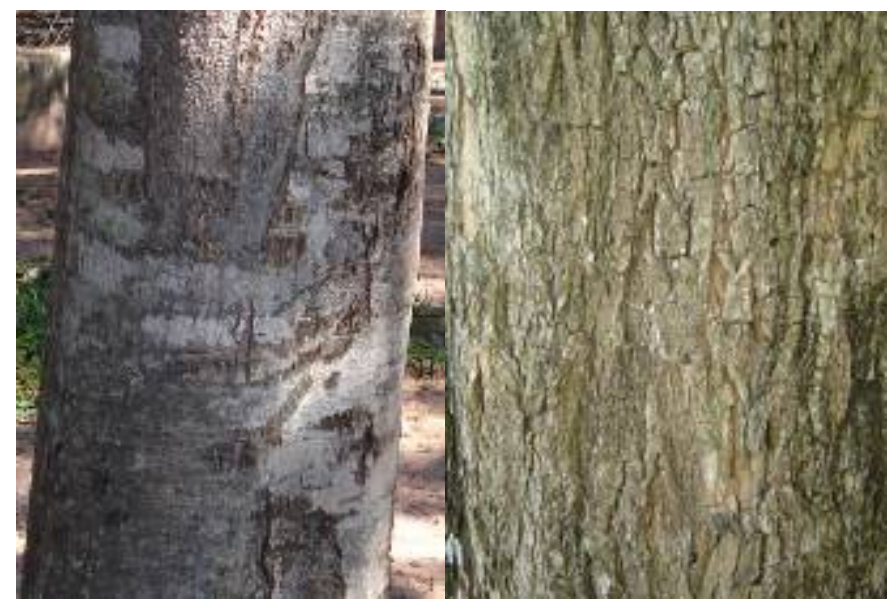

Fonte: w3.ufsm.br/hebarioflorestal, timblindim.wordpress.com

Figura 1 - (a) ramos ortotrópicos e plagiotrópicos, (b) folíolos pequenos e formato oval, (c) flores terminais e não terminais, (d) frutos deiscente-legume e indeiscente-sâmara, (e) superfície menos enrugada e muito enrugada de sibipiruna e tipuana, localizadas no campus da ESALQ/USP 


\section{Medidas de interceptação}

A precipitação foi coletada por meio de baldes de 7 litros de capacidade de água, com diâmetro de $23 \mathrm{~cm}$ e altura de $22 \mathrm{~cm}$, e medida imediatamente após cada evento, por provetas graduadas de $100 \mathrm{ml}$ e $1.000 \mathrm{ml}$.

O escoamento pelo tronco foi coletado por meio de canaletas feitas por espuma de poliuretano, colocadas em cada tronco até o término do experimento. Essa espuma é líquida e quando é agitada e aplicada no tronco, expande e alguns minutos depois fica rígida (LIKENS, EATON, 1970). Antes de enrijecer, foi manuseada até adquirir formato de canaletas, onde escoaram as águas para os baldes.

Os baldes foram distribuídos aleatoriamente, tanto no centro como na extremidade da copa e amparados por estacas de ferro de $30 \mathrm{~cm}$, para mantê-los fixos ao longo do período experimental. A medição da proveta graduada foi registrada em prancheta, após meia ou uma hora a cada evento de chuva. Posteriormente, os valores volumétricos coletados foram tabulados em milímetros de altura de água.

A precipitação total (PT), que é medida em terreno aberto, foi coletada por cinco baldes distribuídos em área próxima de cada indivíduo ou no grupo, com, aproximadamente, 5 a $20 \mathrm{~m}$ de distância entre eles. A precipitação interna (PI), que é a chuva que atinge o solo, tanto pelas gotas que passam diretamente pelas aberturas existentes entre as copas, como as que respingam dessas, também foi medida por baldes abaixo de cada copa, sendo que, cinco baldes foram colocados em sua extremidade e os outros cinco no centro. O escoamento pelo tronco das árvores $(\mathrm{Et})$, igualmente, foi medido por baldes que foram colocados sob as canaletas formadas pela espuma de poliuretano (Figura 2).

A medição do escoamento pelo tronco, nos indivíduos isolados, foi feita, com número de baldes de acordo com a capacidade de escoamento de água e tamanho do diâmetro à altura do peito (DAP). Nas espécies em grupo, foi usada a média aritmética dos três troncos para conversão do volume coletado em milímetro de altura de água.

$\mathrm{O}$ volume de cada indivíduo isolado e do grupo foi medido pela média aritmética dos cinco baldes colocados em terreno aberto (PT), na extremidade e no centro ( $\mathrm{PI})$ das copas. 

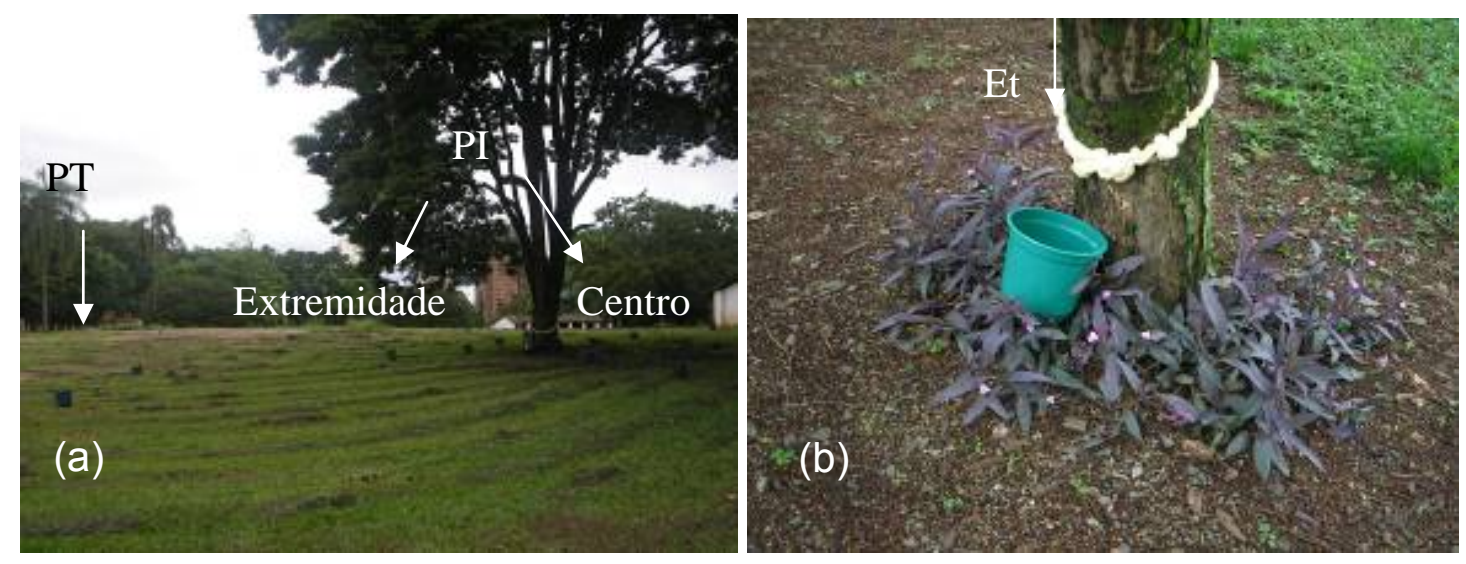

Figura 2 - Distribuição dos baldes no terreno aberto, na extremidade e centro da copa (a) e o escoamento pelo tronco, conduzidos por espuma de poliuretano na espécie de Caesalpina pluviosa DC. (sibipiruna) (b)

A interceptação ou perda por interceptação (I) é a água interceptada pelas copas que não atinge o solo; pode ser calculada pela diferença entre a precipitação total (PT) e a precipitação interna $(\mathrm{PI})$, sem levar em conta o aspecto físico ou a evaporação para a atmosfera.

\section{Análise dos dados}

A análise de regressão foi realizada para comparação entre precipitação interna, escoamento pelo tronco e interceptação com a precipitação total, nos indivíduos de tipuana e sibipiruna

\section{RESULTADOS E DISCUSSÃO}

No período experimental foram medidos 31 eventos em 21 dias, com variações de chuvas entre o mínimo de 0,21 $\mathrm{mm}$ até o máximo de $30,82 \mathrm{~mm}$. A maioria das coletas realizadas foi em único evento por dia, mas sete delas ocorreram em dois ou três eventos diários, com intervalo de meia a uma hora entre eles. Dessa forma, podese considerar que as coletas de eventos únicos diários tiveram intervalos secos de até 24 horas.

O centro da copa apresentou maior média de interceptação do que a extremidade, com exceção de um indivíduo sibipiruna (S1), Figura 3. O resultado já era previsto, pois a extremidade da árvore sofre grande influência dos ventos. Entretanto, no trabalho de Geiger (1961), observou que houve maior porcentagem de interceptação na extremidade da copa em plantas resinosas. Essa diferença pode estar relacionada 
com o tipo de folha, como acículas (pontiagudas em espécies resinosas, por exemplo, folha de Pinus) e folhosas nas demais e não causada pela velocidade do vento que foi insignificante no trabalho.

No experimento, a velocidade do vento foi menor que $15 \mathrm{Km} / \mathrm{h}$ na maioria dos eventos e não afetou a interceptação tanto no centro como na extremidade. Tal fato foi verificado pela baixa correlação exponencial e quadrática $\left(R^{2}\right.$ menores que 0,09$)$ entre a velocidade do vento e a interceptação.

Teklehaimanot et al. (1991) verificaram um aumento na condutância aerodinâmica em árvores com espaçamento maior, em Picea sitchensis (Bong.) Carriére na Escócia, responsável por considerável perda de interceptação. Ainda, a evaporação da água interceptada é comandada pelo déficit de saturação do ar e pelo influxo vertical do ar mais quente e mais seco. Desse modo, as árvores isoladas estão condicionadas a terem taxas de evaporação mais altas do que em florestais densas (DAVID, 2002).

Para a mesma autora, a perda por interceptação em florestas densas está bem definida, por não ter tanta influência do meio, enquanto que, para árvores isoladas urbanas é um fator limitante. As maiores taxas de evaporação durante o período chuvoso pode refletir na diferença de condições climáticas (contribui para mais chuva), de energia disponível ou rugosidade aerodinâmica (ventos).

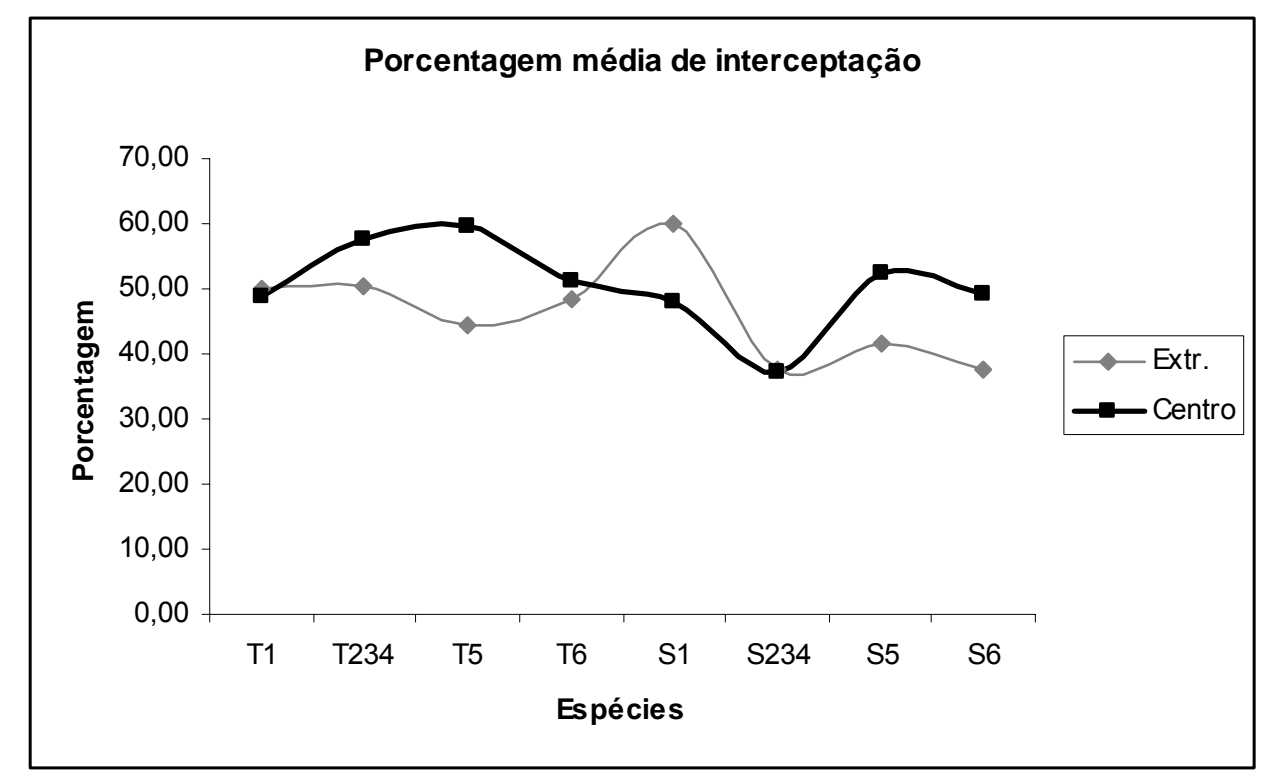

Figura 3 - Porcentagem média de interceptação nas duas espécies: tipuanas isoladas (T1, T5 e T6) e grupo (T123) e sibipirunas (S1, S2 e S3) e grupo (S123), durante o período de janeiro e fevereiro, no campus da ESALQ/USP 
As árvores isoladas têm maior probabilidade de apresentar menor porcentagem de interceptação devido à velocidade do vento, que diminui a precipitação interna em certos locais abaixo da copa. A perda por interceptação pode também ser influenciada pela sua fenologia, diversidade e densidade de espécies num mesmo ambiente. Enquanto que, para florestas plantadas, as perdas por interceptação serão muito mais homogêneas e menores devido ao espaçamento (3X2) sistematizado, considerando a mesma espécie e idade (LIMA, 1986).

No experimento, foi notada maior freqüência de eventos com intensidade baixas, menores que 2,5 mm (Tabela 1) e de acordo com Xiao et al. (2000), os eventos com intensidade menores que 1,5 mm tiveram baixa correlação linear entre PI e PT, devido a sua grande variabilidade que ocorre no início de umedecimento da copa. Para esses eventos de baixa intensidade, a maior parte da PI é notada a partir do gotejamento através da abertura das copas.

Tabela 1 - Intensidade e freqüência dos eventos coletados nos indivíduos de sibipiruna e tipuana de janeiro e fevereiro de 2007, no campus da Escola Superior de Agricultura "Luiz de Queiroz", em Piracicaba/SP

\begin{tabular}{cc}
\hline Intensidade $(\mathrm{mm})$ & Freqüência \\
\hline $0-2,5$ & 13 \\
$2,6-5,0$ & 8 \\
$5,1-10,0$ & 5 \\
$10,1-20,0$ & 3 \\
$20,1-30,0$ & 2 \\
Total & 31 \\
\hline
\end{tabular}

Para melhor aferir a variabilidade, os dados de precipitação interna, escoamento pelo tronco e interceptação, em relação à precipitação total, foram submetidos à análise de regressão linear e quadrática, que podem ser conferidos na Figura 4.

A precipitação interna, tanto na extremidade como no centro da copa apresentou elevada correlação com a quantidade de precipitação total, com menor valor do coeficiente de determinação $\left(R^{2}\right)$ de 0,9011 , para a extremidade da copa de tipuanas (Figura 4a). A PI no centro da copa foi maior devido ao acúmulo de água nos galhos posicionados mais na horizontal, que confere um crescimento plagiotrópico.

O escoamento pelo tronco teve baixa correlação com a quantidade de precipitação total, com $\mathrm{R}^{2}$ igual a 0,5208, na Figura 4b. Para Xiao et al. (2000), em pequenas intensidades, o escoamento pelo tronco é controlado pela umidade inicial da copa e se a superfície estiver saturada, o escoamento depende da quantidade de chuva 
que poderá ocorrer, por exemplo, quando a quantidade de chuva for maior que a superfície de armazenamento da copa, o Et é proporcional a chuva.

Apesar da baixa correlação, houve proporção entre Et e PT que pode estar relacionada com as coletas realizadas em dois ou três eventos por dia, onde a superfície estava saturada.

A correlação entre interceptação, na extremidade e centro da copa, em relação à precipitação total, foi baixa, com $\mathrm{R}^{2}$ menor de 0,3233 para extremidade da copa (Figura 4c). Como ocorreu na PI, onde o centro da copa acumulou mais água e, portanto, teve maior interceptação.

Essa baixa correlação entre o escoamento pelo tronco e a interceptação pode estar relacionada à grande distância que havia entre os indivíduos; desse modo, ocorre menos interação de interceptação de água entre as copas do que a observada em florestas naturais.

(a)

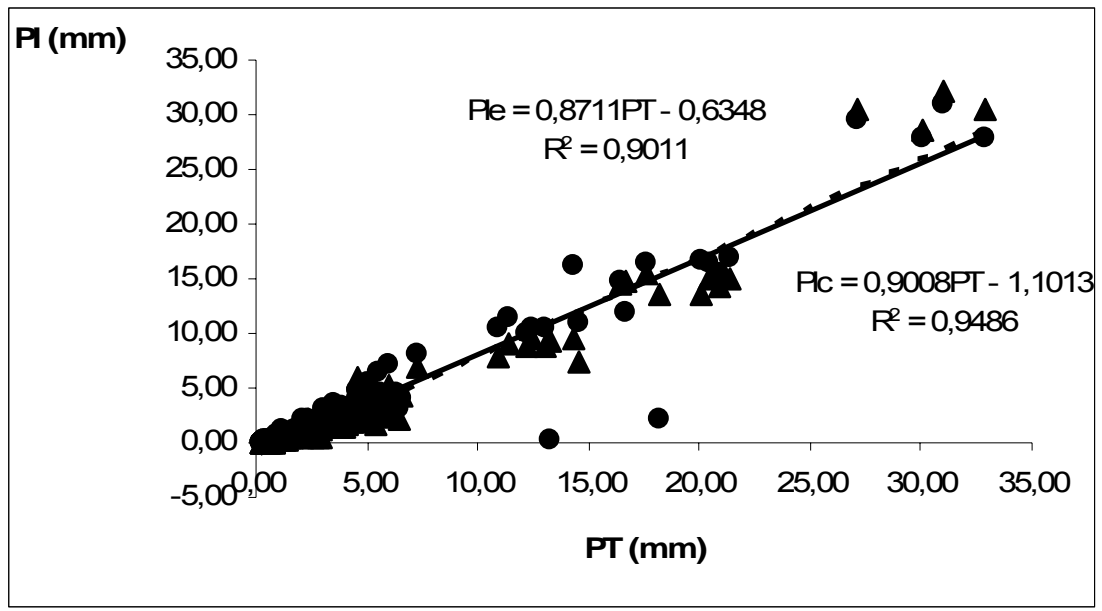

(b)

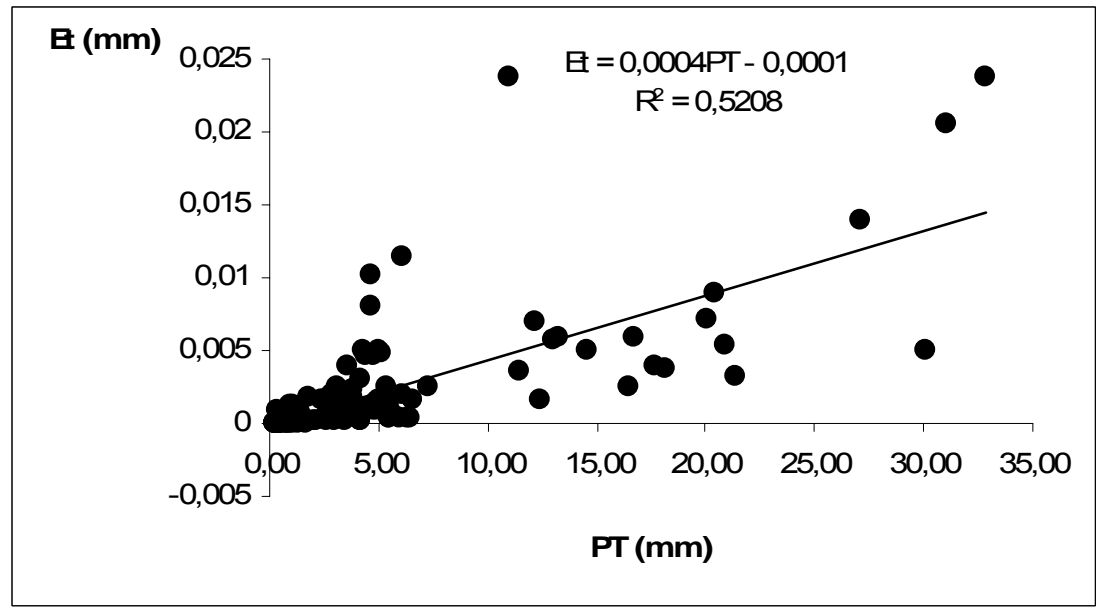


(c)

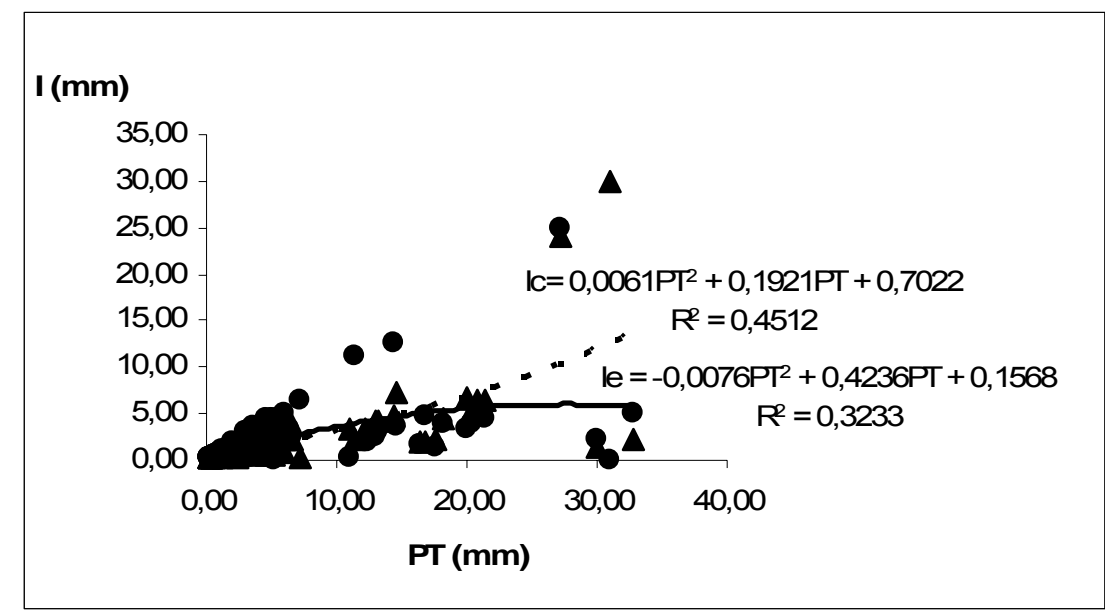

- - extremidade da copa

$\Delta$---- centro da copa

Figura 4 - Tipuanas: (a) relação entre a precipitação interna na extremidade (Ple) e centro da copa (PIc) e a precipitação total (PT), (b) escoamento pelo tronco (Et) e precipitação total (PT) e (c) interceptação na extremidade (le) e centro (Ic) e precipitação total (PT). Período de janeiro e fevereiro de 2007, no campus da ESALQ/USP

A sibipiruna apresentou alta correlação para a extremidade da copa, com maior valor do coeficiente de determinação $\left(R^{2}\right)$ de 0,9801 (Figura 5a), ao contrário do que foi observado, anteriormente, no centro da copa de tipuana, em que a correlação foi maior, o que pode estar relacionado com a arquitetura da copa, que influenciou, diretamente, na precipitação interna nas duas espécies.

Embora as tipuanas tenham apresentado tronco rugoso e epífitas, foi nas sibipirunas que observou-se menor escoamento pelo tronco, uma vez que, estas tiveram baixa correlação com a quantidade de precipitação total, com $R^{2}$ igual a 0,3162 (Figura 5b).

No trabalho de Návar (1993), ele mediu o escoamento pelo tronco em três espécies arbustivas mais cultivadas no México e verificou que a medida do escoamento pelo tronco, na espécie Diospyrus texana Scheele, foi maior do que em Acacia farnesiana (L.) Willd. e Prosopis laevigata (Willd.) M. Johnston. Esse fato ocorreu devido ao ângulo de inclinação dos galhos de $D$. texana que eram maiores que $70^{\circ}$ e $80^{\circ}$, como pode ser verificado em galhos de sibipiruna, que são mais voltados à posição vertical do que em tipuana (Figura 1a). Tal observação foi constatada no trabalho de Xiao et al. (2000), na espécie Pyrus calleryana Dcne, que também obteve maior escoamento pelo tronco e, consequentemente, menor interceptação, pois seus galhos são, predominantemente, verticais. 
Quanto à interceptação da copa, a sibipiruna apresentou o mesmo comportamento que a tipuana (Figura $5 \mathrm{c}$ ), com baixa correlação. Entretanto, a sibipiruna apresentou maior coeficiente de determinação $\left(R^{2}\right)$ de 0,4608 e 0,4221 , tanto para o centro como para a extremidade da copa, ao contrário do que foi observado nas tipuanas (Figura 4c) e, também, na porcentagem média de interceptação em S1 (Figura $3)$.

Esse fato pode estar relacionado com a quantidade de folhas e galhos, pois a sibipiruna tem maior área foliar, o que é suficiente para apresentar essa pequena diferença na interceptação, enquanto que, na tipuana existe maior área ocupada por galhos.

$\mathrm{Na}$ interceptação, foi realizada a análise de regressão quadrática devido à baixa correlação linear e pode estar relacionada com variabilidade de alguns eventos com valores menores que $1,5 \mathrm{~mm}$, na qual reflete na umidade inicial da copa. Por outro lado, em eventos com valores maiores, a copa segura, apenas, uma pequena proporção da precipitação total e, consequentemente, a interceptação diminui, como pode ser observado em ambas as espécies, nas Figuras $4 \mathrm{c}$ e $5 \mathrm{c}$.

(a)

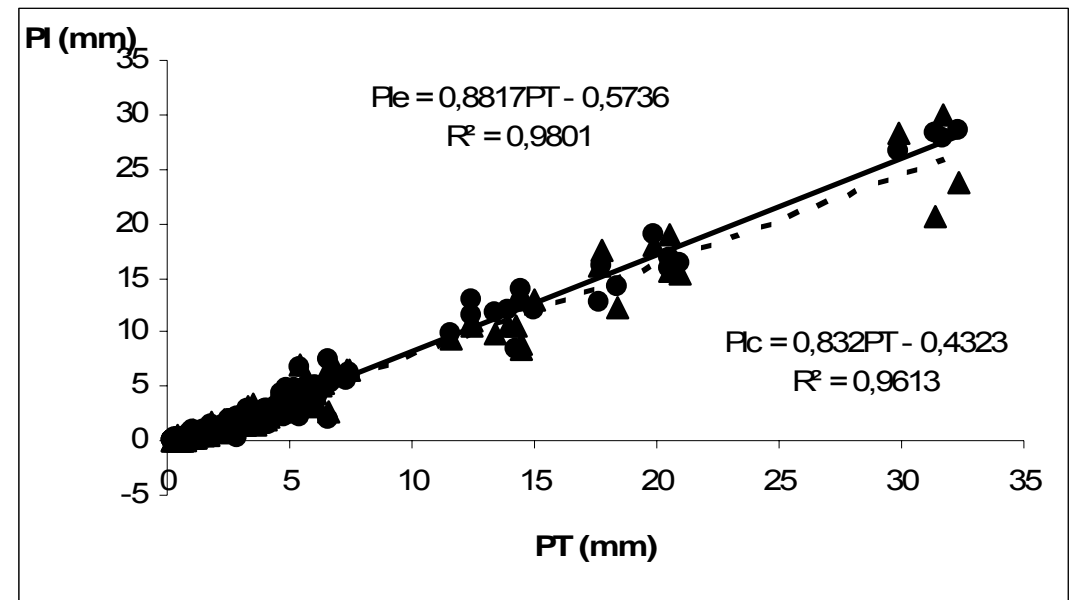


(b)

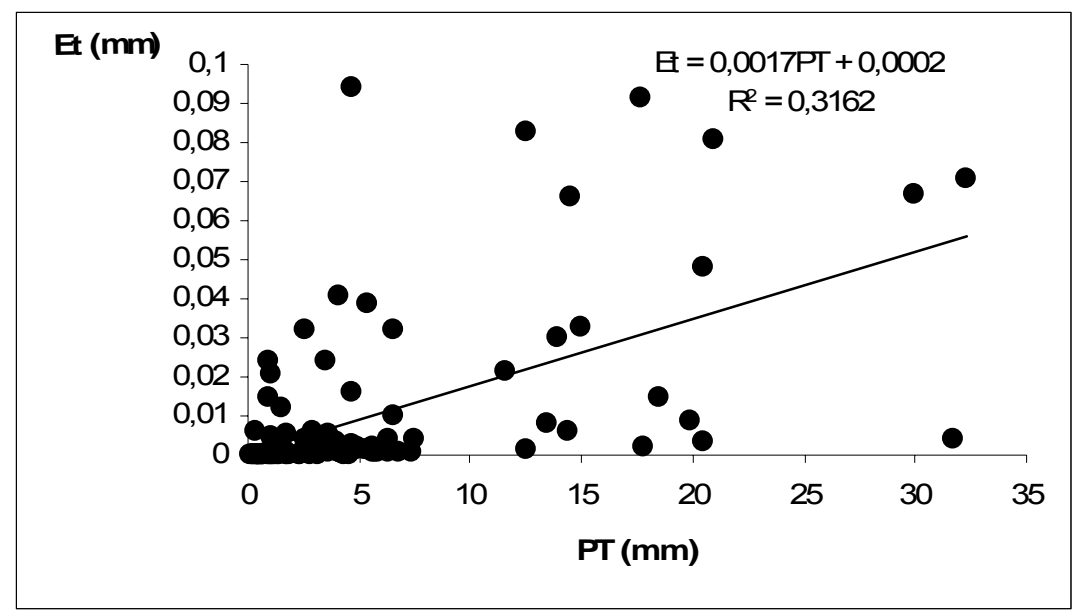

(c)

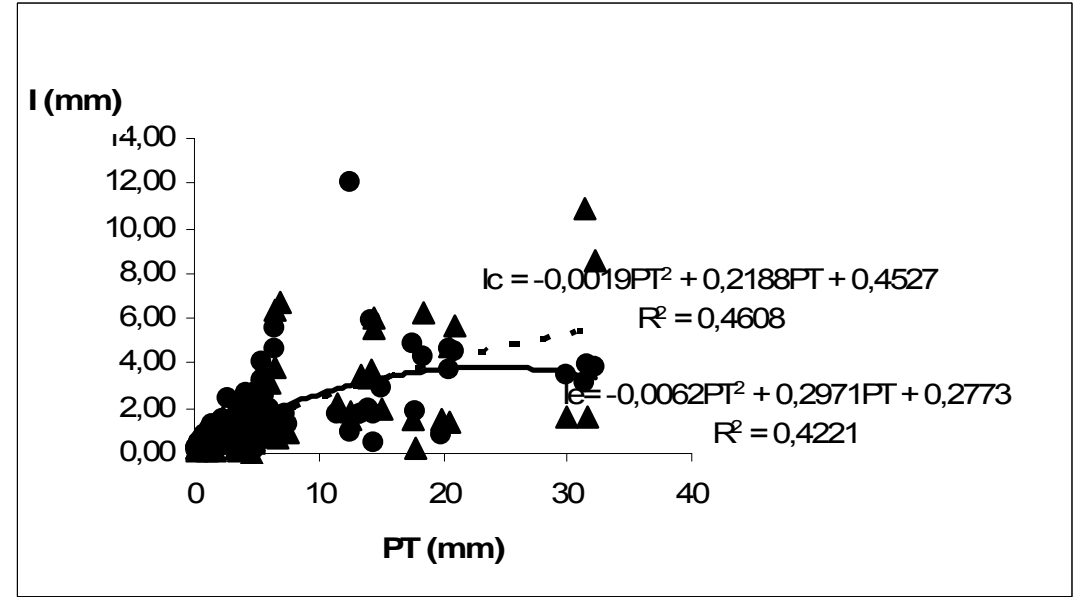

- - extremidade da copa

$\Delta$---- centro da copa

Figura 5 - Sibipirunas: (a) relação entre a precipitação interna na extremidade $(\mathrm{Ple})$ e centro da copa (PIc) e a precipitação total (PT), (b) escoamento pelo tronco (Et) e precipitação total (PT) e (c) interceptação na extremidade (le) e centro (Ic) e precipitação total (PT). Período de janeiro e fevereiro de 2007, no campus da ESALQ/USP

Diante dos dados apresentados, verificou-se a necessidade de observar, concomitantemente, os dados de todas as espécies e de todas as condições dos eventos para melhor explicação das análises, e também estudar a influência da arquitetura das árvores na interceptação da água da chuva. 


\section{CONCLUSÕES}

As duas espécies têm grande potencial para minimizar os efeitos causados pelas enchentes e podem ser indicadas para o plantio em calçadas, desde que seja seguido o manejo adequado no plantio e na manutenção.

A sibipiruna e a tipuana tiveram a capacidade de interceptar até $60 \%$ de água na extremidade e no centro da copa, respectivamente. A arquitetura da copa pode ter influenciado na interceptação.

De modo geral, a tipuana apresentou maior capacidade de interceptação devido a maior presença de galhos do que sibipiruna.

\section{REFERÊNCIAS BIBLIOGRÁFICAS}

AMORIM, M. C. de C. T. O Clima urbano de Presidente Prudente-SP. 2000, 374p. Tese (Doutorado em Geografia), Faculdade de Filosofia Letras e Ciências Humanas, Universidade de São Paulo, 2000.

CENTENO, J. A. S.; ANTUNES, A. F. B.; TREVIZAN, S.; CORREA, F. Mapeamento de áreas impermeáveis usando uma metodologia orientada a regiões e imagens de alta resolução. Revista Brasileira de Cartografia, Rio de Janeiro, n. 55/01, p. 48-56, Nov. 2003.

DAVID, T. S. Interceptação da precipitação em árvores isoladas de Quercus rotundifolia Lam. Silva Lusitana, Lisboa, v.10, n.1, p. 1-15, Jun. 2002.

ENDRESS, P. K. Diversity and evolutionary biology of tropical flowers. $1^{0}$. Ed., Cambridge: Great Britain, 1994. 511 p.

GEIGER, R. O clima da camada do ar junto ao solo. $4^{\circ}$. Ed., Fundação Calouste Gulbenkian: Lisboa, 1961. 556 p.

GIACOMINI, V. Por um urbanismo mais humano. Correio da Unesco. Rio de Janeiro. v. 9, n. 6, p.23, 1981.

HALLÉ, F.; OLDMAN, R.A.A.; TONLINSOM, P. B. Tropical trees and forest: an architectural analysis. Berlin: Springer Verlag, 1978. 200 p.

LIMA, W. P. Interceptação da chuva pela floresta. São Paulo: Universidade de São Paulo, p. 109 -123, 1986.

LIKENS, G. E.; EATON, J. S. A polyurethane stemflow collector for trees and shrubs. Ecology, New York, v.51, n.5, p. 938-939, Sep. 1970.

LOMBARDO, M. A. Ilha de calor nas metrópoles: O exemplo de São Paulo. São Paulo: Hucitec, 1985, 244p. 
LORENZI, H. Árvores brasileiras: manual de identificação e cultivo de plantas arbóreas nativas do Brasil. Nova Odessa: Plantarum, 1992, p. 148.

MARTINS, M. A. G.; OLIVEIRA, D. M. T. Morfo-anatomia e ontogênese do fruto e da semente de Tipuana tipu (Benth.) O. Kuntze (Fabaceae: Faboideae). Revta. Brasl. Bot., São Paulo, v.24, n.1, p.109-121, mar. 2001.

MENDONÇA, F. de A. O clima e o planejamento urbano de cidades de porte médio e pequeno: proposição metodológica para estudo e sua aplicação $1^{a}$ cidade de Londrina/PR.1994. 300p. Tese (Doutorado) - Faculdade de Filosofia e Letras e Ciências humanas, Universidade de São Paulo, São Paulo, 1994.

NÁVAR, J. The causes of stemflow variation in three semiarid growing species of Northeastern México. Journal of Hidrology, Illinois, v. 145, p. 175-190, Oct. 1993.

OKE, T. Boundary Layer Climates. London: Methuen, 1978, 369p.

SPRIN, A. W. O Jardim de Granito: A natureza no desenho da cidade. São Paulo: Edusp, 1996, 345p.

TEKLEHAIMANOT, Z.; JARVIS, P. G.; LEDGER, D. C. Rainfall interception and boundary layer conductance in relation to tree spacing. Journal of Hydrology, Amsterdam, v.123, p. 261-278, July 1991.

VIDAL, W. N.; VIDAL, M. R. R. Botânica Organografia. $3^{\text {a }}$ ed. Imprensa Universitária: Viçosa - Minas Gerais, p. 114, 1992.

XIAO, Q.; McPHERSON, E. G.; USTIN, S. L.; GRISMER, M. E.; SIMPSON, J. R. Winter rainfall interception by two mature open-grow trees in Davis, California. Hydrological Processes, Davis, v.14, p.763-784, June. 2000.

ZUFFO, A. C. LEME, P. E. GRADEX E SANTA BÁRBARA: método híbrido para cálculo de vazão de projeto para macro drenagem urbana. Disponível em http:// www.artigocientifico.com.br. Acesso em: 10 jun. 2006. 